\title{
Peptidergic Nerve Terminals Associated with the Central Lacteal Lymphatics in the Ileal Villi of Dogs
}

\author{
Sanae Ichikawa ${ }^{1}$, Daijo Kasahara ${ }^{1}$, Toshihiko Iwanaga ${ }^{2}$, Shigeo Uchino ${ }^{1}$ and Tsuneo FuJiTa $^{2}$ \\ Department of Anatomy ${ }^{1}$, Tokyo Madical College, Tokyo; and Department of Anatomy ${ }^{2}$, Niigata University School of Medicine, \\ Niigata, Japan
}

Received May 2, 1991

Summary. Nerve fibers in the villi of the canine ileum were studied with special reference to their relation to the central lacteal. Immunohistochemically demonstrable nerve fibers containing substance $P$ (SP) and calcitonin gene-related peptide (CGRP) were rather more numerous in the villi of the ileum than in those of the duodenum, as observed in our previous study (ICHIKAW A et al., 1991). They were distributed beneath the epithelium and associated with smooth muscle fibers. Besides these localizations, immunoreactive fibers were gathered, especially at the middle of the hight of the villus, close to the endothelial cells of the central lacteal. This particular distribution of nerves was more evident in the ileum than in the duodenum.

Electron microscope observation indicated beaded fibers containing large cored (peptidergic) and small clear vesicles coursing closely under the lacteal endothelium, partly intercalated by a basement membrane and partly in direct contact. The nerve fibers often penetrated the endothelial cell, being directly surrounded by its cytoplasm. Although the above-described findings essentially coincide with our previous observations in canine duodenum (ICHIKAW a et al., 1991), the present study in the ileum demonstrated occasional nerve fibers protruding into the lacteal lumen with a knob-like swelling.

It is suggested that the SP and CGRP-containing nerves in problem might be sensory in nature, possibly monitoring mechanical information from the lumen and wall of the central lacteal. At the same time, these nerves are suggested to be secretory in nature, releasing the peptides to exert unknown effects upon the lacteal wall and its vicinity, presumably in response to luminal and mural stimuli.

In our previous report on the canine duodenum, immunohistochemical techniques were employed to demonstrate the occurrence of numerous CGRP- and
SP-immunoreactive nerve fibers in the wall of the central lacteals of villi. Under the electron microscope we found an intimate relationship of the nerve terminals with the endothelium of central lacteal lymphatics, and were able to identify CGRP- and SP-immunoreactive granules in the nerves (ICHIKAWA et al., 1990, 1991).

In the course of further studies in the canine intestine, we noticed that the villi in the ileum were richer in the peptidergic nerves than in the duodenum and showed a more intimate relation to the lacteal wall.

The present study thus aims to examine the villi of the canine ileum by electron microscopy, using serial ultrathin sections of the central lacteal. This topographical study will be combined with immunohistochemical identification of neuropeptides in the nerves in question at light and electron microscopic levels.

\section{MATERIALS AND METHODS}

\section{Histology and immunohistochemistry}

After examining routine paraffine sections of canine ileum mainly stained with hematoxylin and eosin, immunostaining for neuropeptides was performed with following techniques.

Six adult mongrel dogs $(7-10 \mathrm{~kg}$ in body weight) were used in this study. Under deep anesthesia with pentobarbital sodium, the animals were perfused with Ringer solution via the thoracic aorta, and then with $4 \%$ paraformaldehyde in $0.1 \mathrm{M}$ phosphate buffer, $\mathrm{pH}$ 7.4. Tissues taken from the ileum were minced, immersed in both the same fixative for $6 \mathrm{~h}$ and in a $30 \%$ sucrose solution for two days. The specimens were rapidly frozen in liquid nitrogen and cut at a 
$15 \mu \mathrm{m}$ thickness in a cryostat. These methods have been detailed in our previous paper (ICHIKAWA et al., 1991).

Immunohistochemical examinations of the cryostat sections were made with antisera against SP, CGRP, VIP, GRP, NPY and galanin by the use of the $\mathrm{ABC}$ (avidin-biotion complex) method. The sources of the antibodies and detailed data on the techniques have been noted elsewhere (ICHIKAWA et al., 1991).

For electron microscopy, immunostained sections were post-fixed in $1 \% \mathrm{OsO}_{4}$ for $30 \mathrm{~min}$ and embedded in Araldite. Ultrathin sections stained with uranyl acetate were observed by a JEOL 100 CXII electron microscopy.

Electron microscopy with serial ultrathin sections Serial ultrathin sections were produced using three adult mongrel dogs (7-10 kg in body weight), deeply anesthetized with an intravenous injection of pentobarbital sodium. The animals were then perfused, via the thoracic aorta, with Ringer solution followed by $2 \%$ glutaraldehyde and $4 \%$ paraformaldehyde (in a $0.1 \mathrm{M}$ phosphate buffer solution). The ileum was then dessected and cut into small pieces. The pieces were further fixed in the same aldehyde fixative for 2-3 h, to be postfixed in $1 \%$ osmium tetroxide for $2 \mathrm{~h}$. Afterwards they were dehydrated with ethanol, substituted with propylene oxide, and embedded in Quetol 651 (Nissin EM).

Serial ultrathin sections were cut transversely across the long axis of the villus from their base to the tip. These sections were stained with uranyl acetate and lead citrate and examined under a JEOL 100 CXII electron microscope.

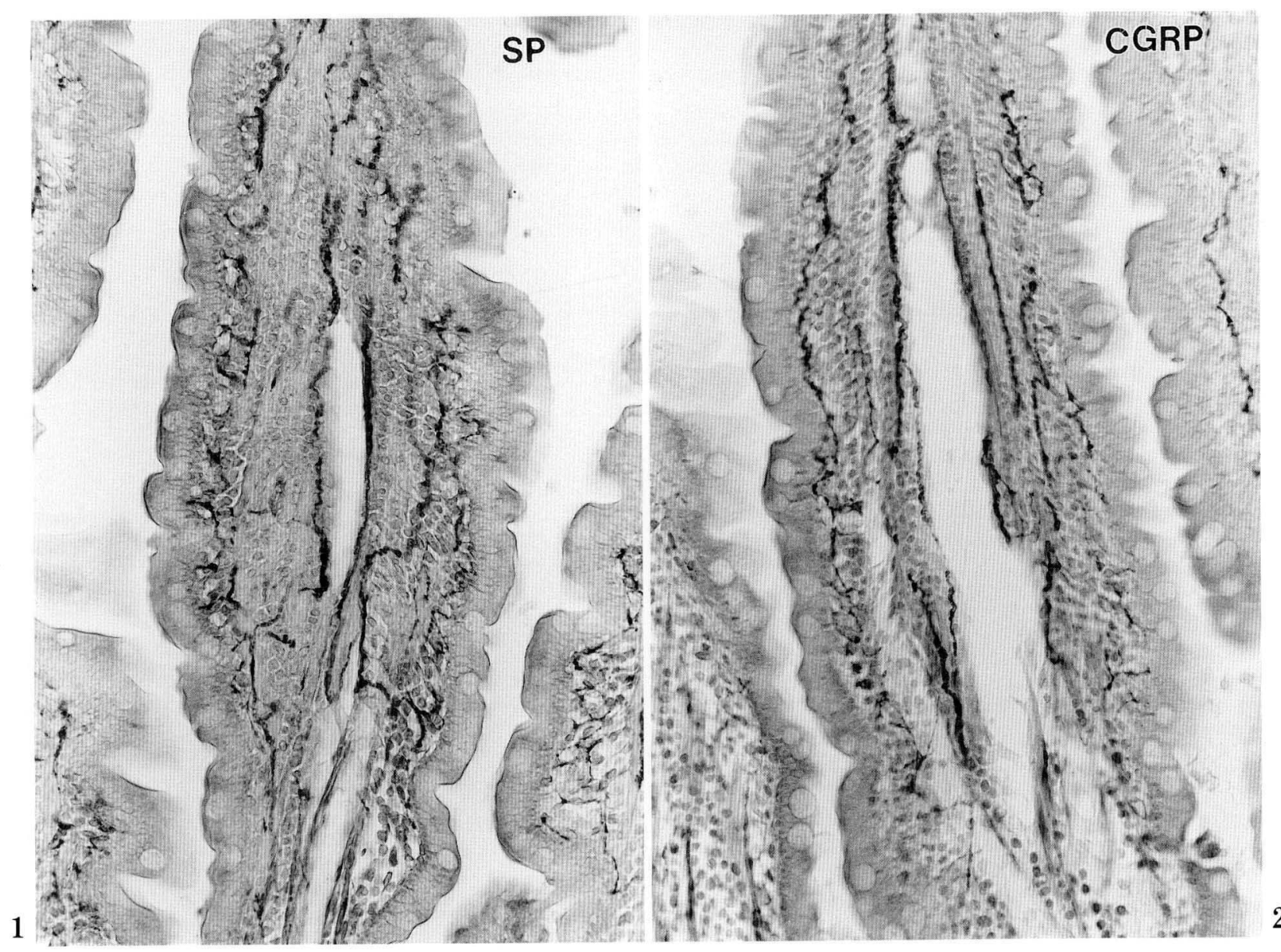

Figs. 1 and 2. SP- (Fig. 1) and CGRP-immunoreactive nerves (Fig. 2) in the ileal villi of dogs. ABC immunostaining. Numerous immunoreactive nerve fibers with varicosities are densely distributed throughout the ileal villi. $\times 220$ 


\section{OBSERVATIONS}

\section{Light microscopy and immunohistochemistry}

The villi of the canine ileum were conspicuously tall structures $(500 \mu \mathrm{m})$ containing a well-developed central lacteal along the axis. It was lined with a thin, continuous endothelium, and the lamina propria surrounding it contained rather numerous and strong smooth muscle cells which were not in direct contact with the endothelium. Small profiles of blood capillaries were found beneath the epithelium of the villus.

The immunohistochemical staining of neuropeptides indicated that nerve fibers immunoreactive for SP, CGRP, VIP were most numerous in the villi. GRP, NPY, Met-EK-8 and galanin-positive fibers were fewer.
The VIP-immunoreactive fibers were closely related to the smooth muscles and subepithelial vascular beds, and only occasionally appeared around the central lacteals.

Nerve fibers containing SP and CGRP were numerously recognized in the lamina propria of the villi. They ran mainly longitudinally, while anastomosing obliquely with each other forming a network. The fibers appeared beaded, showing more or less marked swellings: these were immunostained more intensely than the slender portions.

The SP- and CGRP-immunoreactive fibers could be divided into three groups according to their distribution. They were firstly gathered beneath the epithelium, secondly along individual smooth muscle fibers, and finally and noteworthily closely surrounding the central lactereal (Figs. 1-4). The last group of fibers
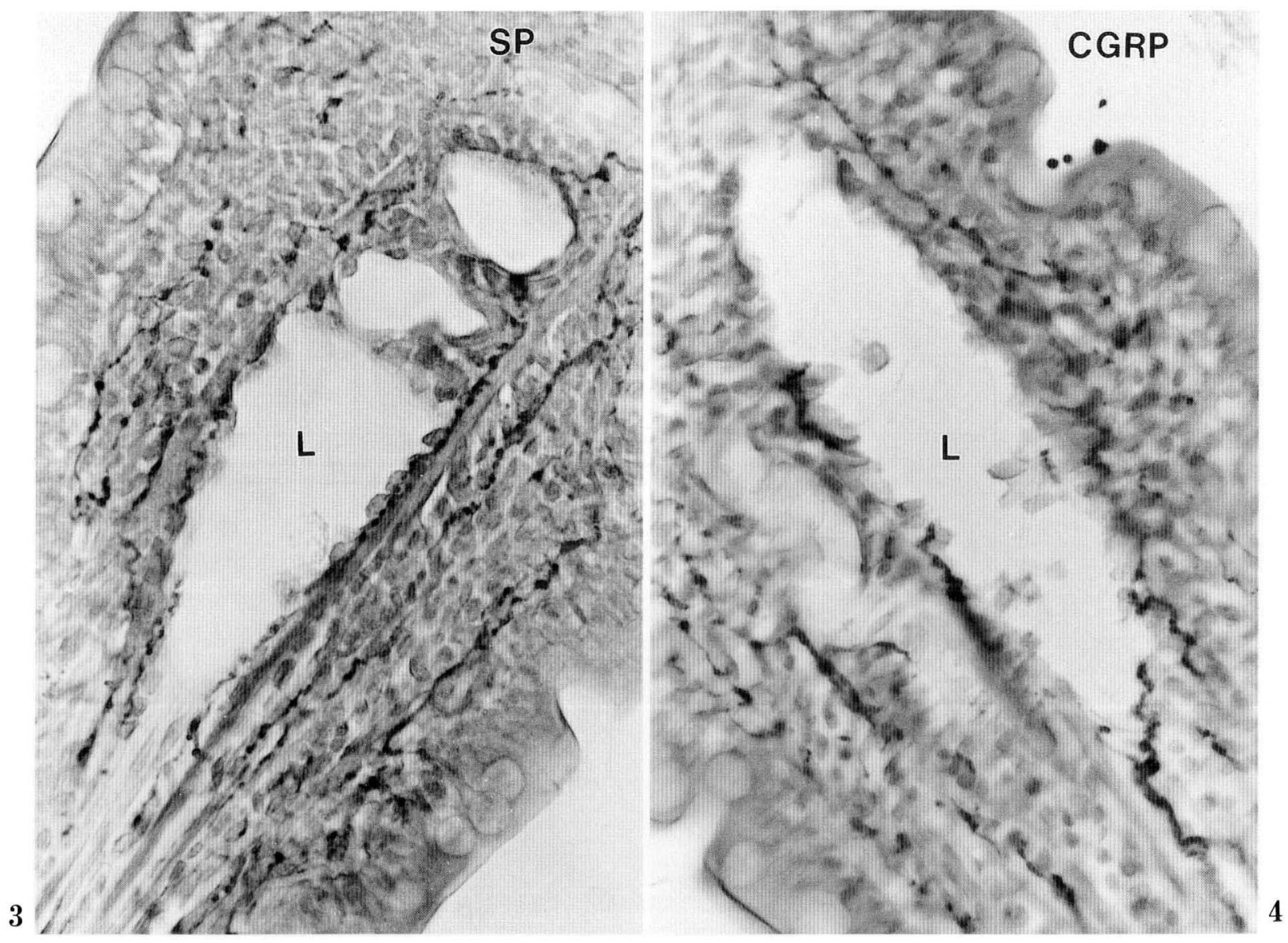

Figs. 3 and 4. The middle of the height of the villus. SP- (Fig. 3) and CGRP-immunoreactive nerves (Fig. 4 ) run along the bundles of smooth muscle fibers, some of them showing close association with the endothelial cells of the central lacteal $(L)$. ABC immunostaining. $\times 440$ 

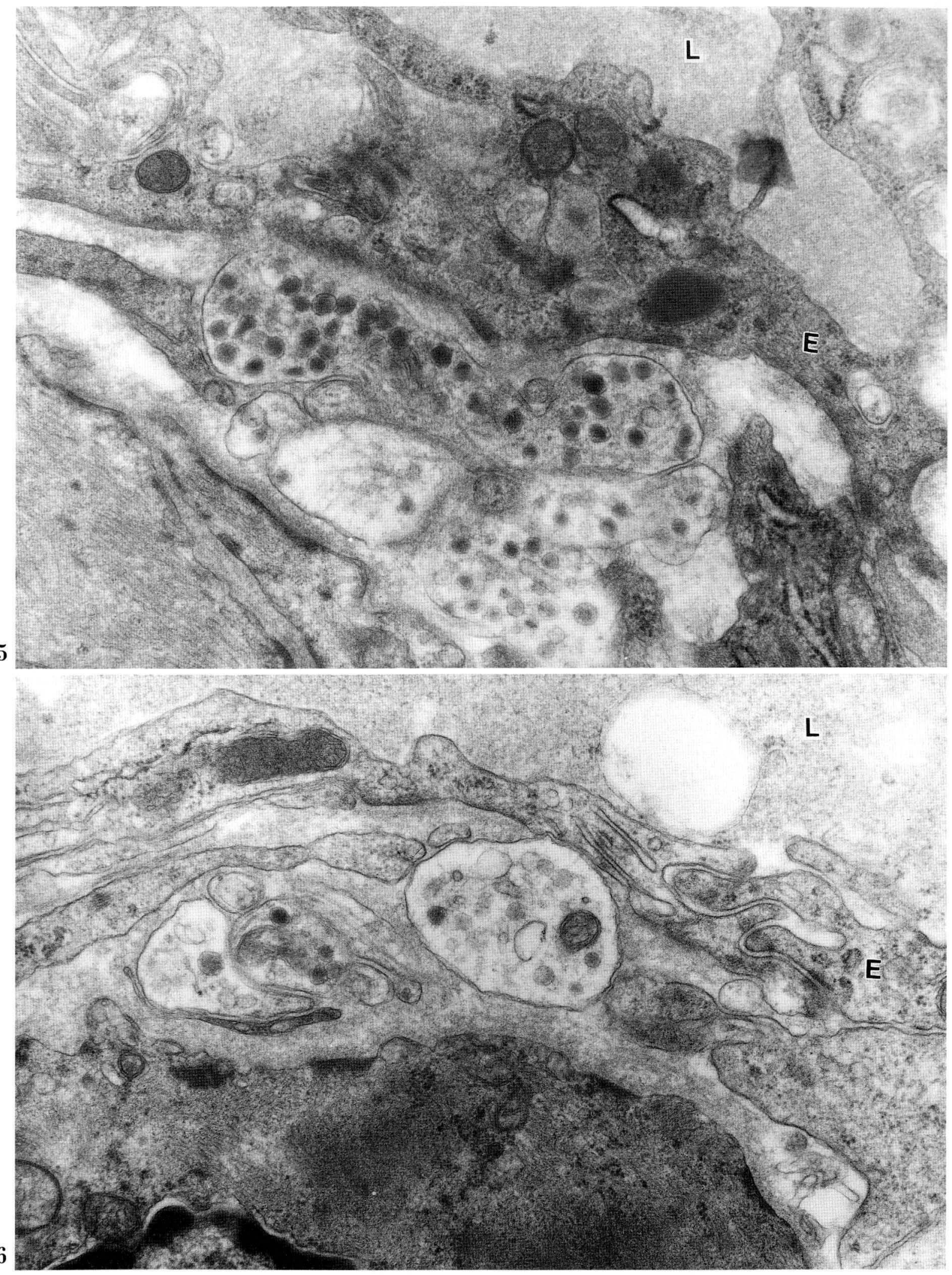


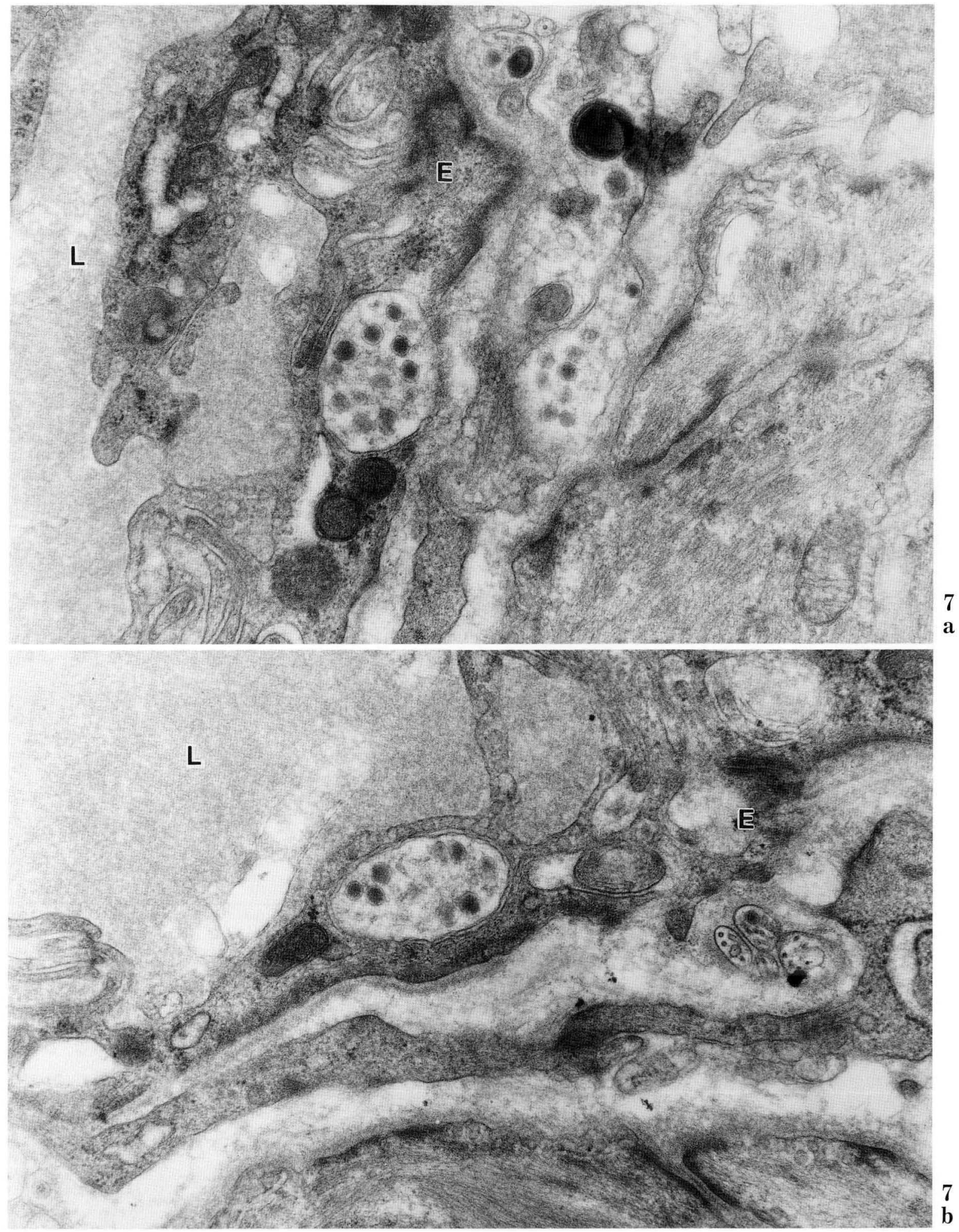

Figs. 5-8. Electron micrographs showing swollen peri-lymphatic nerve fibers located directly beneath the endothelium $(E)$, either intercalated by a basement membrane (Fig. 5) or directly without its intercalation (Fig. 6). Some fibers penetrate the endothelium (Fig. 7a). An oval swollen profile is surrounded by an endothelial cell (Fig. 7b). A knob-like nerve swelling protrudes into the lacteal lumen $(L)$ (Figs. 8a, b). Figs. 7a, b and Figs. 8a, b, respectively, represent two near, though not adjacent, serially cut sections. Figs. 5-8: $\times 40,000$ 


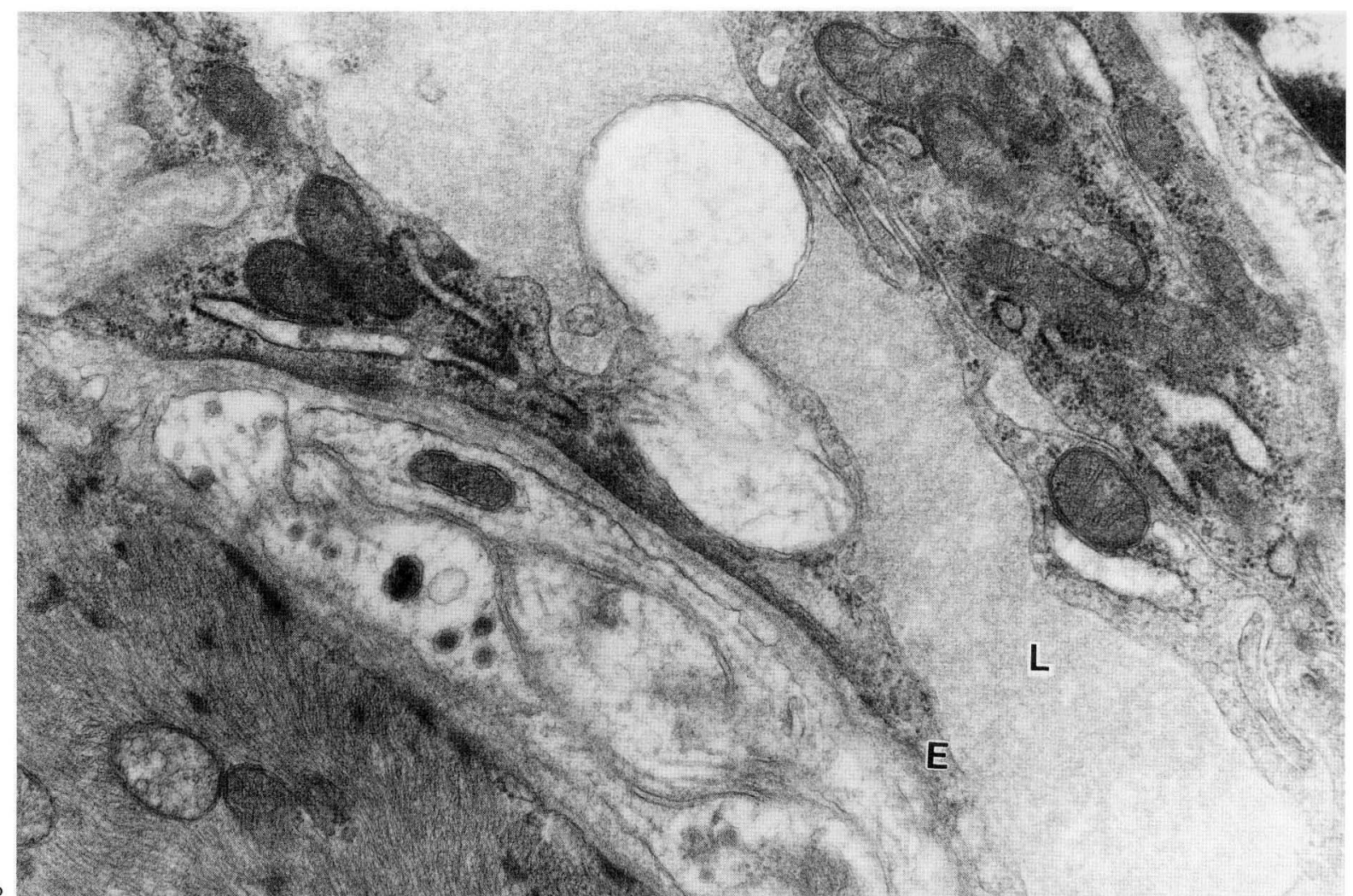

8

a

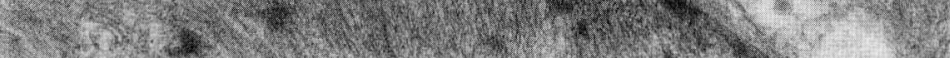

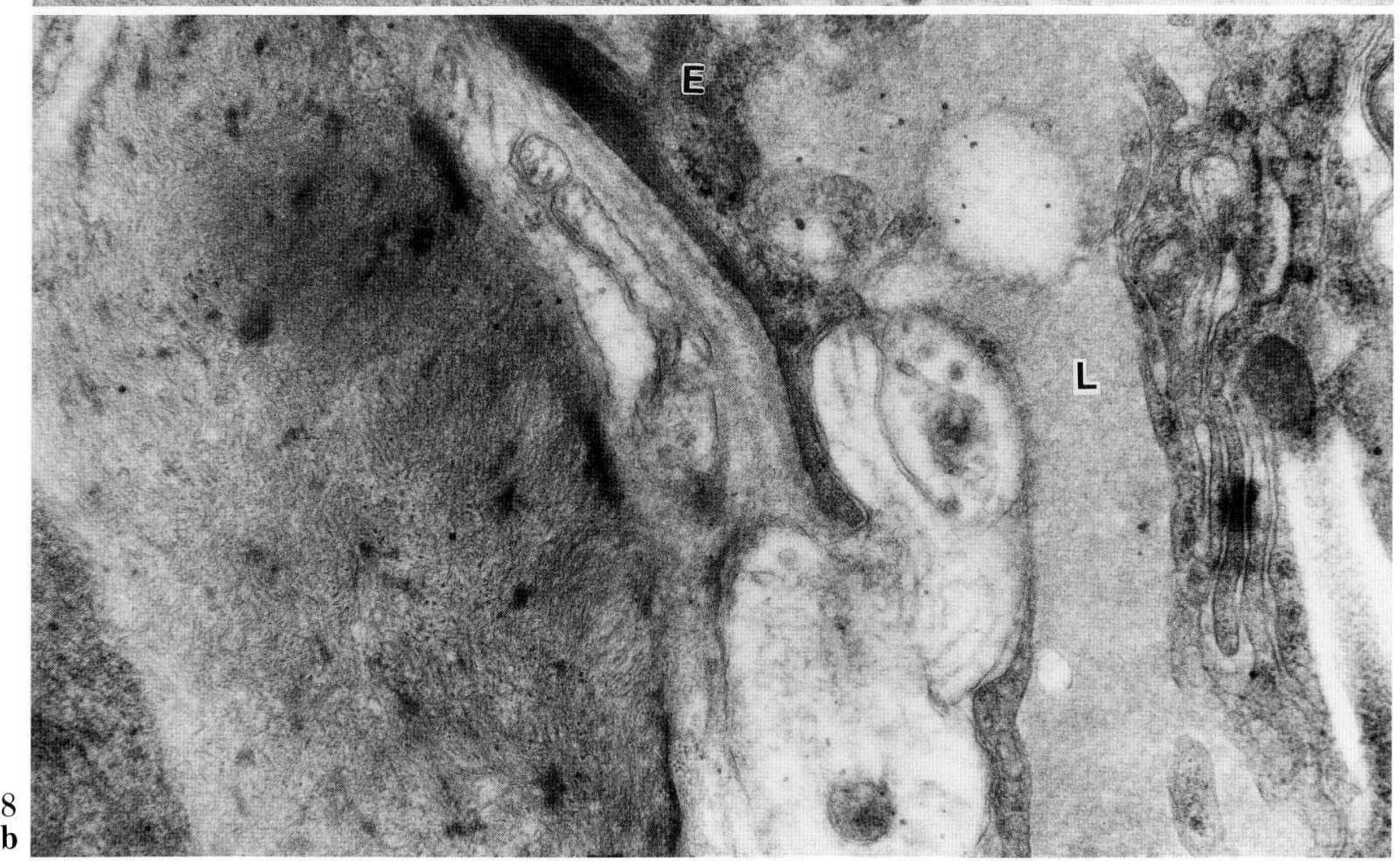

Fig. 8. Legend on p. 315. 

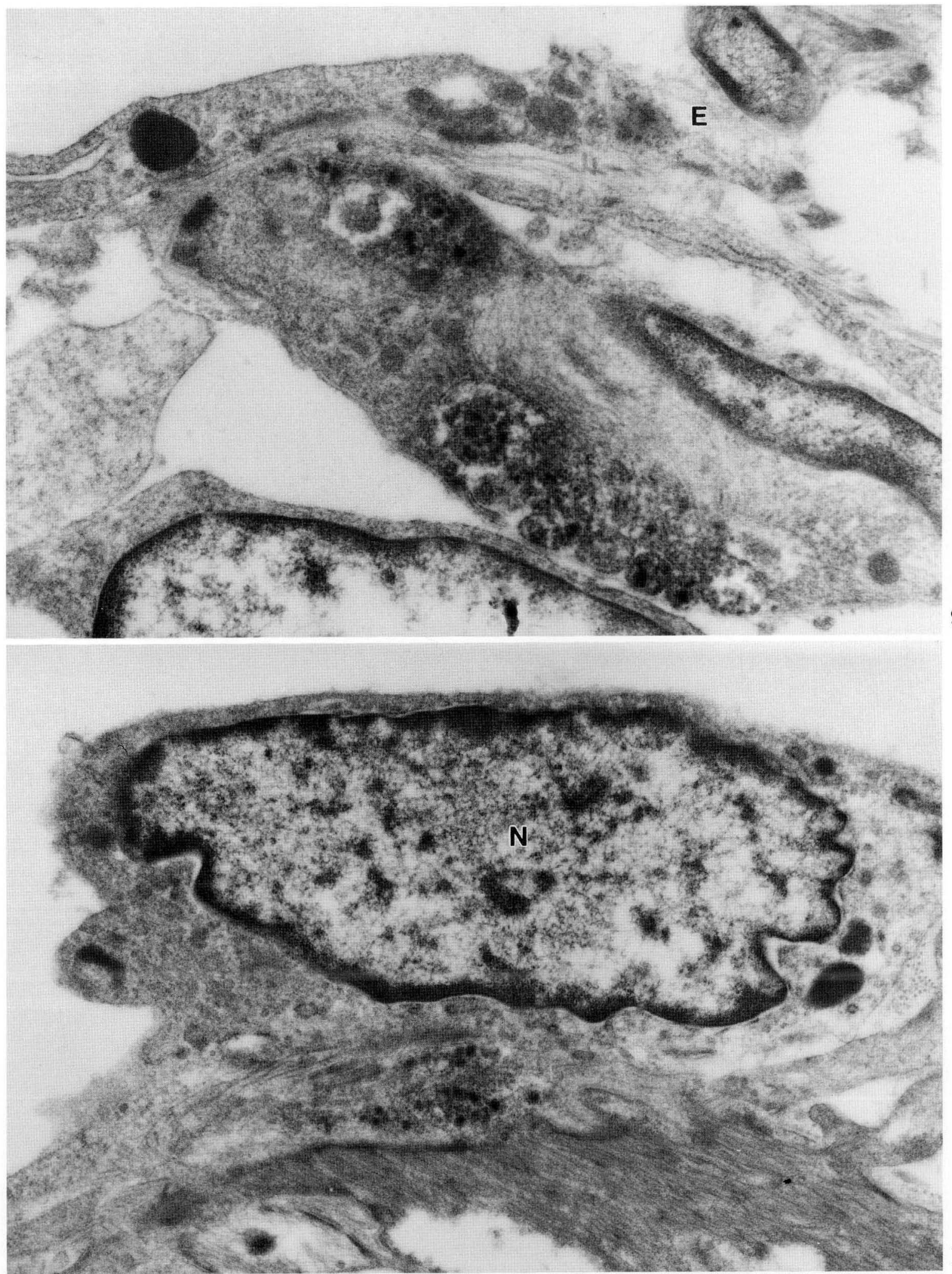

Figs. 9 and 10. Immuno-electron micrographs showing the topographical relationship of the central lacteal endothelium (E) and CGRP- (Fig. 9) and SP-immunoreactive fibers (Fig. 10). CGRP- and SP-immunoreactivities are demonstrated in the subendothelial and intraendothelial nerve fibers, respectively. $N$ nucleus of an endothelial cell. Fig. 9: $\times 28,000$, Fig. 10: $\times 20,000$ 
was clearly noticed at the middle of the height of the villus. As these peri-lymphatic nerves do not appear to have been detailed in previous literature, this paper will concentrate on their structure and nature.

\section{Serial ultrathin sections}

The partially swollen peri-lymphatic fibers as demonstrated by light microscopy could easily be confirmed under the electron microscope. They were located directly beneath the endothelium, either intercalated by a basement membrane (Fig. 5) or directly without its intercalation (Fig. 6). Some fibers further penetrated the endothelium, often showing an oval, swollen profile surrounded by the cytoplasm of the endothelial cell (Fig. 7a, b). Observation of horizontally cut serial sections indicated that such an association of nerves and the central lacteal was localized predominantly, if not exclusively, at the intermediate villus hight.

The nerve fibers, both subendothelial and intraendothelial ones, contained numerous large cored vesicles $(60-90 \mathrm{~nm})$ intermingled with small vesicles $(30-35 \mathrm{~nm})$. The granules and vesicles in the nerves were more numerously demonstrable in the present ileal materials than in the duodenal villous nerves reported previously (ICHIKAWA et al., 1991).

A knob-like nerve swelling was occasionally recognized protruding into the lymphatic lumen (Fig. 8a, b). In some cases the nerve appeared to be covered by a very thin cytoplasm of the endothelium, whereas in others it was completely naked and devoid of any coverage. One remarkable finding was that such a terminal knob appeared clear and homogeneous, showing only a few vesicles or other structures. A few neurotubules irregularly extending into the knob through its proximal constriction could be recognized.

\section{Immunohistochemistry (electron microscopy)}

Immunohistochemical staining at the electron microscopic level demonstrated SP- and CGRP-immunoreactivities in the subendothelial, intraendothelial and intraluminal nerve fibers. A few fibers, however, were immunonegative for both neuropeptides. Careful observation of adjacent sections suggested that the immunoreactivities for both peptides resided in identical nerve fibers.

The SP- and CGRP-like immunoreactivities were localized in the large cored vesicles, whereas the small vesicles and cytoplasmic structures remained immunonegative (Figs. 9, 10).

\section{DISCUSSION}

Recent immunocytochemical studies of intestinal innervation have indicated the occurrence of nerve fibers containing neuropeptides including VIP, SP, NPY, SOM and CGRP in the lamina propria of different mammals (CosTA et al., 1980; SCHULTZBERG et

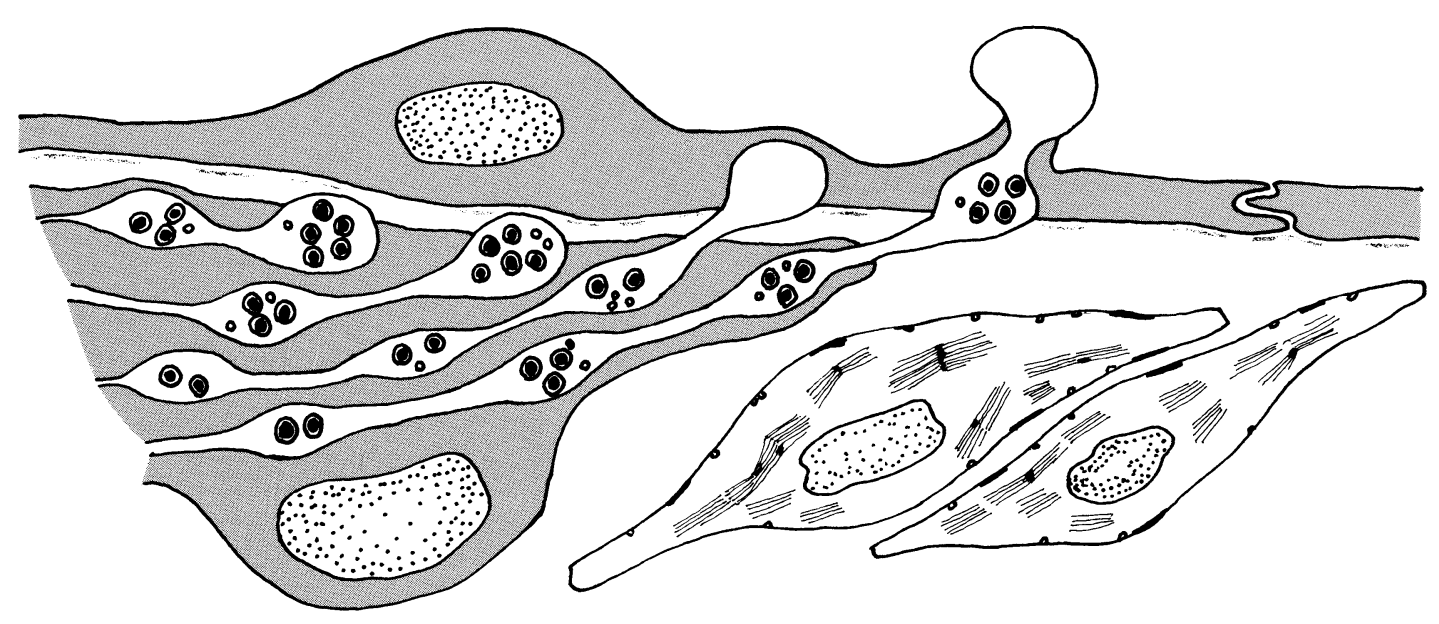

Fig. 11. Schematic representation of beaded nerve fibers which are in different states of association with the endothelium of the central lacteal. 
al., 1980; TANGE, 1983; FURNESS et al., 1985; FURNESS and CosTA, 1987). Our previous and present studies in the canine small intestine confirm this occurrence of nerve fibers in the villi. Among these neuropeptides, this report as well as the previous one concentrate on $\mathrm{SP}$ and CGRP. As the previous study by electron microscopy of identical sections subsequently stained with anti-CGRP and anti-SP antisera indicated, and as our impression obtained by careful comparison of adjacent sections of the present materials suggest, it is most likely that identical nerves are immunoreactive for $\mathrm{SP}$ and CGRP in the ileal as well as duodenal villi.

As is widely known, nerves mainly course beneath the epithelium and along smooth muscle fibers in the lamina propria of the villus (FURNESS and COSTA, 1980, 1987; BURNSTOCK, 1970, 1986). However, nerve fibers running close to the endothelial wall of the central lacteal as demonstrated in our previous and present observations do not seem to have been noticed in previous literature. In this context a report by ITO et al. (1990) seems worthy of mention, who noted the occurrence of some nerve fibers around lymphatics in the interlobular connective tissue of rat liver.

The present study in the ileal villi showed numerous nerve fibers approaching and penetrating the endothelium of the central lacteal. This remarkable finding coincides with that in the upper small intestine reported in our previous paper. However, the present finding differs from the previous one in two points. Firstly, we were able to find more numerous large cored vesicles in the above mentioned nerves in the ileum than in those of the upper intestine. Secondly, we encountered several profiles of knob-like nerve terminals protruding into the lacteal lumen; such a structure could not be found in the upper intestine.

The functional significance of the nerve fibers supplying the lymphatic wall as well as protruding into the lumen is difficult to surmise. As the co-existence of SP and CGRP is a rather common feature of sensory fibers (GiBBins et al., 1985), the nerves supplying the central lacteal may possibly represent sensory fibers. A rounded swelling of nerve terminals in vascular walls has been presumed by some authors to be a baroreceptor, although an accumulation of small mitochondria, which was missed in the present finding, was noticed in such a terminal in many of the previous reports (REES, 1967; CHIBA, 1972; BöCK and GORGAS, 1976; TAHA et al., 1983).

Even though the nerve fibers in question might be sensory in nature, it is most likely that the peptides - SP and CGRP - as well as other - presumably classic - types of nerve transmitters might be re- leased from the terminals, either directly to the endothelium or indirectly by a paracrine fashion to the vicinal cells.

All these problems remain to be explored in future studies. The present finding on the hitherto unknown distribution and structure suggesting nervous regulation of the central lacteal wall and possibly also monitoring the luminal and/or mural information of the lacteal, will hopefully stimulate structural and functional studies of the intestinal villi.

Acknowledgements. The authors are grateful to Dr. Masato OKUBO for technical assistance and helpful discussion, and to Miss Mieko NiIzuma for her technical assistance.

\section{REFERENCES}

Böck, P. and K. GoRGas: Fine structure of baroreceptor terminals in the carotid sinus of guinea pigs and mice. Cell Tiss. Res. 170: 95-112 (1976).

Burnstock, G.: Structure of smooth muscle and its innervation. In: (ed. by) E. Bülbring, A. F. Brading, A. W. Jones and T. TomitA: Smooth muscle. Edward Arnold, London, 1970 (p. 1-69).

- Autonomic neuromuscular junctions: Current developments and future directions. J. Anat. 146: 1-30 (1986).

Chiba, T.: Fine structure of the baroreceptor nerve terminals in the carotid sinus of the dog. J. Electron Microsc. 21: 139-148 (1972).

Costa, M., A. C. Cuello, J. B. Furness and R. Franco: Distribution of enteric neurons showing immunoreactivity for substance $\mathrm{P}$ in the guinea-pig ileum. Neuroscience 5: 323-331 (1980).

Furness, J. B. and M. Costa: Types of nerves in the enteric nervous system. Neuroscience 5: 1-20 (1980).

- : Arrangement of the enteric plexuses; Transmitter neurochemistry of enteric neurons. In: The enteric neurons system. Churchill Livingstone, 1987 (p. 6-23; p. 55-89).

Furness, J. B., M. Costa, I. L. GibBins, I. J. LIEWELLYN-SMith and J. R. OLIVER: Neurochemically similar myenteric and submucous neurons directly traced to the mucosa of the small intestine. Cell Tiss. Res. 241: 155-163 (1985).

Gibbins, I. L., J. B. Furness, M. Costa, I. MacIntyre, C. J. Hillyard and S. Girgis: Co-localization of calcitonin gene-related peptide-like immunoreactivity with substance $\mathrm{P}$ in cutaneous, vascular and visceral sensory neurons of guinea pigs. Neurosci. Lett. 57: 125-130 (1985).

IChikawa, S., M. Okubo, S. Uchino and Y. Hirata: The intimate association of nerve terminals with the lacteal endothelium in the canine duodenal villi observed by transmission electron microscopy of serial sections. Arch. Histol. Cytol. 53, Suppl.: 137-146 (1990). 
IChikawa, S., M. Shiozawa, T. Iwanaga and S. Uchino: Immunohistochemical demonstration of peptidergic nerve fibers associated with the central lacteal lymphatics in the duodenal villi of dogs. Arch. Histol. Cytol. 54: 241-248 (1991).

Ito, Y., S. MAGARI and M. SAKanaKa: Immunoelectronmicroscopic localization of peptidergic nerve fibers around lymphatic capillaries in the rat liver. Arch. Histol. Cytol. 53, Suppl.: 199-208 (1990).

REES, P. M.: Observations on the fine structure and distribution of presumptive baroreceptor nerves at the carotid sinus. J. Comp. Neurol. 131: 517-548 (1967).

SchultzberG, M., T. Hökfelt, G. Nilsson, L. Terenius, J. F. RehFELD, M. BRown, R. Elde, M. GoldSTEIN and S. SAID: Distribution of peptide- and catecholaminecontaining neurons in the gastro-intestinal tract of rat and guinea-pig: Immunohistochemical studies with antisera to substance $P$, vasoactive intestinal polypeptide, enkephalins, somatostatin, gastrin/cholecystokinin, neurotensin and dopamine $\beta$-hydroxylase. Neuroscience 5: 689-744 (1980).
Taha, A. A. M., E. M. Abdel-Magied and A. S. King: Ultrastructure of aortic and pulmonary baroreceptors in the domestic fowl. J. Anat. 137: 197-207 (1983).

TANGe, A.: Distribution of peptide-containing endocrine cells and neurons in the gustrointestinal tract of the dog: Immunohistochemical studies using antisera to somatostatin, substance $\mathrm{P}$, vasoactive intestinal polypeptide, met-enkephalin and neurotensin. Biomed. Res. 4: 9-24 (1983).

Dr. Sanae ICHIKAWA

Department of Anatomy

Tokyo Medical College

6-1-1 Shinjuku, Shinjuku-ku

Tokyo, 160 Japan

市川早苗

160 東京都新宿区新宿 6 丁目 1-1

東京医科大学

第一解剖学教室 